\title{
Endoplasmic reticulum involvement in yeast cell death
}

\section{Nicanor Austriaco, O. P *}

Department of Biology, Providence College, Providence, RI, USA

\author{
Edited by: \\ Manuela Côrte-Real, Universidade do \\ Minho, Portugal

\section{Reviewed by:} \\ Campbell Gourlay, University of Kent, \\ UK \\ Joris Winderickx, Catholic University \\ of Leuven, Belgium \\ Mark Ramsdale, University of Exeter, \\ UK \\ ${ }^{*}$ Correspondence: \\ Nicanor Austriaco, Department \\ of Biology, Providence College, \\ 1 Cunningham Square, Providence, \\ RI 02918, USA. \\ e-mail: naustria@providence.edu
}

Yeast cells undergo programed cell death (PCD) with characteristic markers associated with apoptosis in mammalian cells including chromatin breakage, nuclear fragmentation, reactive oxygen species generation, and metacaspase activation. Though significant research has focused on mitochondrial involvement in this phenomenon, more recent work with both Saccharomyces cerevisiae and Schizosaccharomyces pombe has also implicated the endoplasmic reticulum (ER) in yeast PCD. This minireview provides an overview of ER stress-associated cell death (ER-SAD) in yeast. It begins with a description of ER structure and function in yeast before moving to a discussion of ER-SAD in both mammalian and yeast cells. Three examples of yeast cell death associated with the ER will be highlighted here including inositol starvation, lipid toxicity, and the inhibition of $\mathrm{N}$-glycosylation. It closes by suggesting ways to further examine the involvement of the ER in yeast cell death.

Keywords: BXI1, endoplasmic reticulum, ER stress, IRE1, UPR, yeast cell death

\section{INTRODUCTION}

In recent years, it has become increasingly clear that yeast cells undergo programed cell death $(\mathrm{PCD})$ in response to a variety of intrinsic and extrinsic stimuli, with characteristic markers associated with apoptosis in mammalian cells (Carmona-Gutierrez et al., 2010). Significantly, yeast orthologs of crucial metazoan apoptotic proteins, which include the metacaspase, Ycalp (Madeo et al., 2002), the yeast AIF1 homolog, Aif1p (Wissing et al., 2004), and the endonuclease G homolog, Nuclp (Buttner et al., 2007), have been identified and linked to yeast cell death suggesting that a core machinery driving PCD is conserved in unicellular eukaryotes (Madeo et al., 2009).

Though significant research has focused on mitochondrial involvement in yeast PCD (Braun and Westermann, 2011), recent work with both Saccharomyces cerevisiae and Schizosaccharomyces pombe has implicated the endoplasmic reticulum (ER) in yeast PCD. This minireview provides an overview of ER stress-associated cell death (ER-SAD) in yeast. It begins with a description of ER structure and function in yeast before moving to a discussion of ER-SAD in both mammalian and yeast cells. It closes by suggesting ways to further examine the involvement of the ER in yeast cell death.

\section{ENDOPLASMIC RETICULUM STRUCTURE IN YEAST}

The ER is the largest membrane-bound organelle in the eukaryotic cell (Friedman and Voeltz, 2011; Hu et al., 2011). It consists of the nuclear envelope and the peripheral ER, a single network of interconnected sheets and tubules, which in yeast is located close to the plasma membrane where it is referred to as the cortical ER. A recent study that imaged the budding yeast ER by transmission electron microscopy and dual-axis electron tomography revealed that it can divided into three structurally distinct major domains: the plasma membrane-associated ER (pmaER), the central cisternal ER (cecER), and the tubular ER (tubER; West et al., 2011).
Molecular components involved in regulating ER structure have recently been identified. Regions of high membrane curvature including the edges of the sheets and the tubules are stabilized by interactions between members of the reticulon family (Rtnlp and Rtn $2 p$ in budding yeast) and members of the DP1/Yoplp family of proteins (Yop1p in budding yeast; Voeltz et al., 2006; Shibata et al., 2010). It is thought that Rtn1p, Rtn2p, and Yop1p, like their mammalian counterparts, stabilize the high curvature of ER tubules by using their double hairpin structure to form wedges and arc-like scaffolds that mold the lipid bilayer into tubules (Shibata et al., 2009, 2010).

Once ER tubules are shaped and formed, they need to be connected to the ER network via homotypic fusion between two identical but apposing membranes. In yeast, homotypic fusion appears to be mediated by the Seylp protein, the ortholog of the mammalian atlastins, a class of GTPases that belong to the dynamin family (Hu et al., 2009; Anwar et al., 2012). Given Seylp's structure, the data suggest that the fusion reaction could be mediated by conformational changes in the Seylp GTPase domains that pull the apposing membranes together forcing them to fuse (Orso et al., 2009; Anwar et al., 2012).

\section{ENDOPLASMIC RETICULUM FUNCTION IN YEAST}

In all eukaryotic cells, the ER performs a variety of functions including protein translocation and folding, lipid synthesis, and calcium homeostasis. In yeast cells, protein transport into the ER can occur via either the signal recognition particle (SRP)-dependent (cotranslational translocation) or the Hsp70pdependent (post-translational translocation) pathway (Zimmermann etal., 2011). Membrane insertion and completion of translocation involve the heterotrimeric Sec61p complex and the ER-lumenal chaperone, Kar2p (or BiP). Kar2p appears to facilitate post-translational insertion of the polypeptide into the Sec61p complex and its translocation via a ratcheting mechanism (Lyman and Schekman, 1996). Once ER client proteins 
have been translocated, they can be folded, modified, and packaged into ER-to-Golgi COPII transport vesicles that form at ER exit sites (ERES; Duden, 2003; Watanabe and Riezman, 2004; Watson and Stephens, 2005). In yeast, ER sheets have a markedly higher ribosome density than tubules suggesting that sheets may be better suited for ribosome binding and protein translocation (West et al., 2011).

Next, the ER serves as the main site for synthesis of three major classes of membrane lipids: sphingolipids, phospholipids, and sterols (Carman and Henry, 2007; Henry et al., 2012). For example, in yeast, most of the biosynthetic steps for triacylglycerols occur in the ER: Gat1p and Gat2p, which are the major glycerol-3-phosphate acyltransferases (GPATs) that catalyze the first step in the synthesis of almost all membrane phospholipids and neutral glycerolipids, localize to both the perinuclear and the cortical ER (Bratschi etal., 2009). Additionally, the two ER membrane proteins, Orm1p and Orm2p, have been shown to be involved in sphingolipid synthesis and phospholipid homeostasis (Han etal., 2010). These are only a few of numerous ERlocalized gene products known to be involved in lipid biosynthesis in yeast.

Finally, the creation of a specifically targeted version of the $\mathrm{Ca}^{2+}$-sensitive photoprotein, aequorin, to the lumen of the yeast ER revealed that this organelle is involved in calcium storage and homeostasis with a steady-state concentration of $10 \mu \mathrm{M}$ free $\mathrm{Ca}^{2+}$ in wild-type yeast cells (Strayle et al., 1999). It is also known that two P-type ATPases are involved in regulating the levels of $\mathrm{Ca}^{2+}$ in the ER including the yeast high-affinity $\mathrm{Ca}^{2+} / \mathrm{Mn}^{2+}$ P-type ATPase, Pmrlp, which pumps cytosolic $\mathrm{Ca}^{2+}$ into the ER and the Golgi (Sorin etal., 1997; Strayle et al., 1999), and the ERlocalized P-type ATPase, Cod1p/Spf1p, which appears to work with Pmrlp to maintain ER function and homeostasis (Vashist et al., 2002). Significantly, $\mathrm{Ca}^{2+}$ levels in the ER have been implicated in retention of resident luminal proteins, in export of secretory proteins, in protein folding and degradation, and in the association of the ER chaperone Kar2p with misfolded proteins (Durr et al., 1998).

\section{ER STRESS-ASSOCIATED DEATH IN MAMMALIAN CELLS}

In mammalian cells, a diverse range of factors can disrupt ER function and lead to ER stress, which if left unchecked can trigger ER-SAD. These include increases in ER-lumenal protein levels that exceed the capacity of ER-resident chaperones, exposure to longchain saturated fatty acids (SFA), alterations in calcium levels in the ER lumen, and disturbances to the ER redox balance (Ron and Walter, 2007; Parmar and Schroder, 2012). In animal cells, ER stress is sensed by three upstream signaling pathways driven by three effector proteins, IRE1, ATF6, and PERK, which are collectively called the unfolded protein response (UPR; Wang et al., 1998; Harding et al., 1999; Urano et al., 2000; Walter and Ron, 2011). Activation of the UPR can alleviate ER stress by synthesizing novel components of the protein folding machinery and by expanding the ER itself (Cox et al., 1997; Schuck et al., 2009). This activated UPR can be divided into three phases: the adaptive, the alarm, and the apoptotic phase. The adaptive phase begins with an immediate and fast response that decreases protein influx into the ER followed by a slower transcriptional response involving downstream transcription factors that upregulate genes encoding ER-resident chaperones, components of the ER-associated protein degradation (ERAD) machinery, and regulators of ER size (Trusina et al., 2008). In many scenarios, the adaptive phase can restore equilibrium between protein load and chaperone capacity within the ER, dampening the UPR. However, in cases of chronic or unresolved ER stress, the UPR continues to a second alarm phase that involves several signal transduction events that move the cell from a pro-survival to a pro-apoptotic state (Tabas and Ron, 2011; Woehlbier and Hetz, 2011). This ends in the final apoptosis phase involving the transcriptional and post-translational activation of the $\mathrm{BH} 3$-only proteins and other BCL2 protein family members that trigger the canonical mitochondrial cell death pathway. Additionally, the BCL2 proteins have been implicated in linking $\mathrm{ER} \mathrm{Ca}^{2+}$ homeostasis and apoptosis (Oakes et al., 2003; Bassik et al., 2004).

Mechanistically, in mammalian cells, the ER-SAD program is mediated largely by the UPR signaling molecules and endonuclease IRE1 $\alpha$, which can transmit both pro-survival and pro-death signals. Indeed, in my view, ER-SAD can be defined as the cell death process that involves IRE1 function. In light of this, it is significant that there are pro- and anti-apoptotic effectors assembled around IRE1 $\alpha$ that are able to control the amplitude and duration of IRE1 $\alpha$ signaling (Woehlbier and Hetz, 2011). For example, IRE1 $\alpha$ signaling can be enhanced at the ER membrane by the formation of a complex between the cytosolic domains of IRE $1 \alpha$ and the BAX-BAK complex, two pro-apoptotic members of the BCL2 family of proteins (Scorrano et al., 2003; Zong et al., 2003). In contrast, IRE1 $\alpha$ signaling can be attenuated by the binding of the ER-localized anti-apoptotic protein, BAX inhibitor-1 (BI-1; Lisbona et al., 2009; Bailly-Maitre et al., 2010; Castillo et al., 2011). Late-phase UPR signaling of IRE1 $\alpha$ can lead to changes in the expression and activity of BCL2 protein family members and therefore to the activation of apoptosis.

Finally, we should note two emerging areas of inquiry involving the role of the ER in cell death. First, several studies in mammalian cells have begun exploring the links between ER and mitochondrial function during PCD. Both organelles form interconnected membrane networks that can influence various cellular processes including cell death (Csordas et al., 2006). More recently, Cardenas and colleagues have shown that $\mathrm{Ca}^{2+}$ transport between the ER and the mitochondria is regulated by the inositol triphosphate receptor, $\mathrm{IP}_{3} \mathrm{R}$, to modulate mitochondrial bioenergetics (Cardenas et al., 2010), a process involving BI-1, an ER-resident protein known to be involved in autophagy and apoptosis (Sano et al., 2012). This may explain the earlier observation that mitochondria preferentially accumulate $\mathrm{Ca}^{2+}$ in regions called mitochondria-associated microdomains (MAMs) where the ER and mitochondria are found in close proximity (Rizzuto et al., 1998). Next, there have been a few published reports that describe the fragmentation of the ER during ER stress and ER-SAD in mammalian cells (Brough et al., 2005; Kucharz et al., 2011a,b; Howarth etal., 2012). Though there is evidence that the loss of the GTPase atlastin 1 can cause ER fragmentation in Drosophila (Orso etal., 2009), the mechanism behind the ER fragmentation associated with ER stress in the mammalian system is still not known. 


\section{ER STRESS-ASSOCIATED DEATH IN YEAST CELLS}

As they do in mammalian cells, a range of intrinsic and extrinsic triggers can disrupt ER function and lead to ER stress and to ER-SAD in yeast (Table 1). Notably, however, in yeast cells, ER stress is only sensed by a single signaling pathway driven by Irelp, which is the most ancient of the three parallel UPR pathways found in the metazoan (Sidrauski and Walter, 1997). Three examples of yeast cell death associated with the ER will be highlighted here, including inositol starvation, lipid toxicity, and the inhibition of $N$-glycosylation.

First, Guerin etal. (2009) reported that the fission yeast, S. pombe, undergoes cell death with apoptotic-like features when it is deprived of inositol, a precursor of numerous phospholipids and signaling molecules. Deleting either $\mathrm{pcal}^{+}$, the gene for the only caspase-like protein in $S$. pombe, or $i r e 1^{+}$, the gene for the only IRE1 homolog, enhanced cell survival in media lacking inositol, suggesting that both genes are involved in the cell death pathway. Interestingly, the ER transmembrane chaperone, calnexin, encoded by the $c n x 1^{+}$gene, has also been implicated in inositol-starvation-induced ER-SAD since overexpressing different portions of the Cnxlp protein can alter the number of dying cells in inositol-starved conditions as measured by several assays (Guerin et al., 2009).

Next, feeding the budding yeast, S. cerevisiae, with extracellular SFA like palmitate (C16:0) triggers ER stress and leads to growth arrest and death (Pineau et al., 2009). Addition of palmitate to the cell culture also alters ER morphology with swelling of the organelle, detachment of the pmaER from the plasma membrane,

Table 1 | ER-Associated Cell Death in Mammalian and Yeast Cells.

\begin{tabular}{|c|c|c|c|}
\hline ER function & Organism & $\begin{array}{l}\text { Triggers of cell death } \\
\text { (select list) }\end{array}$ & $\begin{array}{l}\text { ER proteins } \\
\text { involved }\end{array}$ \\
\hline \multirow{8}{*}{$\begin{array}{l}\text { Protein } \\
\text { translocation } \\
\text { and folding }\end{array}$} & Mammalian & $\begin{array}{l}\text { Protein aggregation } \\
\text { Ischemia reperfusion }\end{array}$ & $\begin{array}{l}\text { IRE } 1 \alpha \\
\text { ATF6 }\end{array}$ \\
\hline & & Beta-mercaptoethanol (BME) & PERK \\
\hline & & Tunicamycin & $\mathrm{Bl}$ \\
\hline & & Dithiothreitol (DTT) & Grp78/BiP \\
\hline & Yeast & Heat shock & Ire1p \\
\hline & & Beta-mercaptoethanol (BME) & Bxi1p \\
\hline & & Tunicamycin & Kar2p/BiP \\
\hline & & Dithiothreitol (DTT) & \\
\hline \multirow{5}{*}{$\begin{array}{l}\text { Lipid } \\
\text { synthesis }\end{array}$} & Mammalian & Elevated free fatty acids (FFA) & $\operatorname{IRE} 1 \alpha$ \\
\hline & & & ATF6 \\
\hline & & & PERK \\
\hline & Yeast & Elevated saturated fatty acids & Ire1p \\
\hline & & (SFA) inositol starvation & Cnx1p \\
\hline \multirow{5}{*}{$\begin{array}{l}\text { Calcium } \\
\text { dynamics }\end{array}$} & Mammalian & Thapsigargin & PERK \\
\hline & & Calcium overload & SERCA \\
\hline & & & Grp78/BiP \\
\hline & Yeast & Calcium starvation & Pmr1p \\
\hline & & Calcium chelators & \\
\hline
\end{tabular}

and in certain cells, the replacement of pmaER by electron-lucent clefts extending throughout the cytoplasm that are visible in the electron microscope. Both the induction of the UPR and the cell death associated with lipid toxicity were abrogated with the addition of the molecular chaperone 4-phenyl butyrate, suggesting that lipid-induced ER stress overburdens the folding machinery in the ER. Notably, lipid toxicity is known to induce apoptosis in mammalian cells (Kharroubi et al., 2004; Diakogiannaki et al., 2008). One paper reports that palmitate induces apoptosis in pancreatic beta cells by activating the IRE1 $\alpha$, PERK, and ATF6 pathways (Cunha et al., 2008).

Finally, Hauptmann et al. (2006) reported that preventing the $N$-glycosylation of yeast proteins, either by mutating critical subunits of the oligosaccharyltransferase (OST) complex in the ER lumen, or by treating the cells with tunicamycin, a drug known to block the ER enzyme UDP- $N$-acetylglucosamine-1- $P$ transferase (Alg7p) that is necessary for $N$-glycosylation, induced an apoptotic-like death in wild-type $S$. cerevisiae cells. The dying cells contained condensed nuclei, fragmented DNA, and externalized phosphatidylserine. Defects in $N$-glycosylation also led both to the appearance of a caspase-like activity that did not require functional yeast metacaspase, Ycalp, and to the production of reactive oxygen species (ROS) that could be diminished by heterologous expression of the human anti-apoptotic protein, Bcl-2. Two years later, the same team reported that the Golgi-localized Kexlp protease is involved in the apoptotic-like cell death linked to defects in $N$-glycosylation (Hauptmann and Lehle, 2008). Deletion of KEX1 diminished the appearance of the caspaselike activity and decreased ROS accumulation in cells cultured in tunicamycin. Notably, the cell death described in these experiments was blocked by the addition of osmotic stabilizers to the culture media.

Strikingly, these studies disagreed with previous findings that had shown that tunicamycin does not induce cell death in wildtype cells unless the calcium-dependent phosphatase, calcineurin, had previously been inactivated (Bonilla et al., 2002; Bonilla and Cunningham, 2003). To resolve this disagreement, Dudgeon et al. (2008) used improved staining methods using both propidium iodide (PI) and FITC-VAD-FMK together instead of FITC-VAD-FMK alone, to analyze the cell death associated with growth in media containing tunicamycin. Their data showed that tunicamycin can induce cell death, but only in cells grown in low osmolyte yeast-peptone-dextrose (YPD) media, and not in cells grown in synthetic media. They also demonstrated that this dying process is not apoptotic in nature. The dying cells lacked two critical hallmarks of apoptosis - both chromatin fragmentation and phosphatidylserine externalization - suggesting that there may have been methodological problems in past efforts to characterize the cell death induced by tunicamycin in S. cerevisiae.

Instead, tunicamycin appeared to trigger two different forms of death in wild-type budding yeast cells, one that is partially dependent on a functional electron transport chain (ETC) and another that is independent of ETC function. Active calcineurin signaling could prevent the former, which is why it has been called calcineurin-less death, but not the latter form of cell death. Significantly, calcineurin-less death in response to tunicamycin 
did not involve any of the apoptosis-associated factors, Ycalp, Nuclp, Nma111p, or Ste20p, strengthening the claim that this death is not apoptotic in nature. Rather, the dying process was regulated by $\mathrm{Cmk} 2 \mathrm{p}$, one of the two $\mathrm{Ca}^{2+} /$ calmodulin-dependent protein kinases, and by Hsp90p, one of the major heat shock chaperones in budding yeast. Finally, a very recent study from the same research team has concluded that tunicamycin leads to cell death by permeabilizing the vacuolar membranes of yeast cells and that this cell death program involves the V-ATPase that acidifies the vacuole (Kim et al., 2012). This tunicamycin-induced cell death involving vacuole membrane permeabilization could be blocked by calmodulin.

In light of the cumulative evidence, in my view, it is clear that tunicamycin leads to cell death, but that this dying process is not apoptotic in nature as had been previously reported. One possible reason for the discrepancy in the literature is the earlier study's failure to distinguish living apoptotic cells from dead necrotic cells, which are known to stain non-specifically with FITC-VAD-FMK (Wysocki and Kron, 2004; Hauptmann et al., 2006). Moreover, the observation reported in the earlier paper that the addition of an osmotic stabilizer like sorbitol is able to block some of the $\mathrm{N}$ glycosylation-linked cell death suggests that this cell death may be lytic rather than apoptotic in nature (Hauptmann and Lehle, 2008). This is not surprising since protein $N$-glycosylation is crucial for cell wall assembly (Lesage and Bussey, 2006; Levin, 2011). Defects in this biochemical pathway would be expected to weaken the cell's ability to maintain its structural integrity.

Finally, can this tunicamycin-induced calcineurin-less cell death in S. cerevisiae properly be called ER stress-associated cell death? It is not clear. As I noted above, in mammalian cells, ER-SAD has been linked to the activation of the UPR and IRE1 function. Though tunicamycin does induce the UPR in budding yeast, it is also apparent that Ire1p is not required for either the pro-death activity of tunicamycin in calcineurin-deficient cells or

\section{REFERENCES}

Anwar, K., Klemm, R. W., Condon, A., Severin, K. N., Zhang, M., Ghirlando, R., Hu, J., Rapoport, T. A., and Prinz, W. A. (2012). The dynaminlike GTPase Seylp mediates homotypic ER fusion in S. cerevisiae. J. Cell Biol. 197, 209-217.

Bailly-Maitre, B., Belgardt, B. F., Jordan, S. D., Coornaert, B., von Freyend, M. J., Kleinridders, A., Mauer, J., Cuddy, M., Kress, C. L., Willmes, D., Essig, M., Hampel, B., Protzer, U., Reed, J. C., and Bruning, J. C. (2010). Hepatic Bax inhibitor-1 inhibits IRElalpha and protects from obesityassociated insulin resistance and glucose intolerance. J. Biol. Chem. 285, 6198-6207.

Bassik, M. C., Scorrano, L., Oakes, S. A., Pozzan, T., and Korsmeyer, S. J. (2004). Phosphorylation of BCL2 regulates $\mathrm{ER} \mathrm{Ca}^{2+}$ homeostasis and apoptosis. EMBO J. 23, 1207-1216.

Bonilla, M., and Cunningham, K. W. (2003). Mitogen-activated protein kinase stimulation of $\mathrm{Ca}^{2}+$ signaling is required for survival of endoplasmic reticulum stress in yeast. Mol. Biol. Cell 14, 4296-4305.

Bonilla, M., Nastase, K. K., and Cunningham, K. W. (2002). Essential role of calcineurin in response to endoplasmic reticulum stress. EMBO J. 21 , 2343-2353.

Bratschi, M. W., Burrowes, D. P., A. L., Kearley, J., and Zaremberg, V. (2009). Glycerol-3-phosphate acyltransferases gat $1 p$ and gat $2 p$ are microsomal phosphoproteins with differential contributions to polarized cell growth. Eukaryot. Cell 8, 1184-1196.

Braun, R. J., and Westermann, B. (2011). Mitochondrial dynamics in yeast cell death and aging. Biochem. Soc. Trans. 39, 1520-1526.

Brough, D., Sim, Y., Thorn, P., and Irvine, R. F. (2005). The structural integrity of the endoplasmic reticulum, and its possible regulation Kulaga, A., Cheung, J. F., Alvarez,

the anti-death activity of calcineurin in these cells (Bonilla et al., 2002). This is in stark contrast to the single published report suggesting that tunicamycin induces an apoptotic-like cell death in S. pombe that appears to partially require the fission yeast Irelp (Guerin et al., 2008).

\section{FUTURE DIRECTIONS}

The study of the ER's role in yeast cell death is in its infancy. It would be interesting to determine if other physiological triggers of yeast cell death like acetic acid or ethanol - triggers not directly linked to ER function - involve the ER. Recently, my laboratory has begun characterizing the yeast BI protein, Bxilp, an ER-localized protein that links the UPR to PCD in S. cerevisiae (Cebulski et al., 2011).Cells lacking BXI1 are not only more sensitive both to ethanol-induced and to glucose-induced PCD, but also have a diminished UPR. Studies linking Bxilp and Ire1p function in yeast are ongoing in my lab. Finally, it will be important to check if PCD alters the yeast's ER structure, and conversely, if mutants that modify ER structure alter the dynamics of yeast cell death. These investigations should uncover the mechanistic links between ER structure, ER function, and cell death in yeast.

\section{ACKNOWLEDGMENTS}

I apologize in advance to my colleagues whose work I could not cite because of the length restrictions of this minireview. I thank Ryan Frazier, David Laprade, Kevin Murphy, James O’Brien, Stephen Rogers, and Alexander Wilcox for helpful comments on the manuscript. Our laboratory is supported by the following grants: NIGMS R15 GM094712, NSF MRI-R2 0959354, two CAFR Faculty Research Development grants from Providence College, and a subcontract from NIH Grant 2 P20 RR016457 awarded to the Rhode Island INBRE Program, for undergraduate student training. Non nisi te, Domine.

by inositol 1,3,4,5-tetrakisphosphate. Cell Calcium 38, 153-159.

Buttner, S., Eisenberg, T., CarmonaGutierrez, D., Ruli, D., Knauer, H. Ruckenstuhl, C., Sigrist, C., Wissing, S., Kollroser, M., Frohlich, K. U., Sigrist, S., and Madeo, F. (2007). Endonuclease $\mathrm{G}$ regulates budding yeast life and death. Mol. Cell 25, 233-246.

Cardenas, C., Miller, R. A., Smith, I., Bui, T., Molgo, J., Muller, M., Vais, H., Cheung, K. H., Yang, J., Parker, I., Thompson, C. B., Birnbaum, M. J., Hallows, K. R., and Foskett, J. K. (2010). Essential regulation of cell bioenergetics by constitutive InsP3 receptor $\mathrm{Ca}^{2+}$ transfer to mitochondria. Cell 142, 270-283.

Carman, G. M., and Henry, S. A. (2007). Special issue: regulation of lipid metabolism in yeast. Biochim. Biophys. Acta 1771, 239-240.

Carmona-Gutierrez, D., Eisenberg, T., Buttner, S., Meisinger, C., Kroemer, G., and Madeo, F. (2010). Apoptosis in yeast: triggers, pathways, subroutines. Cell Death Differ. 17, 763-773.

Castillo, K., Rojas-Rivera, D., Lisbona, F., Caballero, B., Nassif, M., Court, F. A., Schuck, S., Ibar, C., Walter, P., Sierralta, J., Glavic, A., and Hetz, C. (2011). BAX inhibitor-1 regulates autophagy by controlling the IRE1alpha branch of the unfolded protein response. EMBO J. 30, 4465-4478.

Cebulski, J., Malouin, J., Pinches, N., Cascio, V., and Austriaco, N. (2011). Yeast Bax inhibitor, Bxilp, is an ER-localized protein that links the unfolded protein response and programmed cell death in Saccharomyces cerevisiae. PLoS ONE 6, e20882. doi: 10.1371/journal.pone.0020882

Cox, J. S., Chapman, R. E., and Walter, P. (1997). The unfolded protein response coordinates the production of endoplasmic reticulum protein and endoplasmic reticulum membrane. Mol. Biol. Cell 8, 1805-1814. 
Csordas, G., Renken, C., Varnai, P., Walter, L., Weaver, D., Buttle, K. F., Balla, T., Mannella, C. A., and Hajnoczky, G. (2006). Structural and functional features and significance of the physical linkage between ER and mitochondria. J. Cell Biol. 174, 915-921.

Cunha, D. A., Hekerman, P., Ladriere, L., Bazarra-Castro, A., Ortis, F., Wakeham, M. C., Moore, F., Rasschaert, J., Cardozo, A. K., Bellomo, E., Overbergh, L., Mathieu, C., Lupi, R., Hai, T., Herchuelz, A., Marchetti, P., Rutter, G. A., Eizirik, D. L., and Cnop, M. (2008). Initiation and execution of lipotoxic ER stress in pancreatic beta-cells. J. Cell Sci. 121(Pt 14), 2308-2318.

Diakogiannaki, E., Welters, H. J., and Morgan, N. G. (2008). Differential regulation of the endoplasmic reticulum stress response in pancreatic beta-cells exposed to long-chain saturated and monounsaturated fatty acids. J. Endocrinol. 197, 553-563.

Duden, R. (2003). ER-to-Golgi transport: COP I and COP II function (review). Mol. Membr. Biol. 20, 197-207.

Dudgeon, D. D., Zhang, N., Ositelu, O. O., Kim, H., and Cunningham, K. W. (2008). Nonapoptotic death of Saccharomyces cerevisiae cells that is stimulated by Hsp90 and inhibited by calcineurin and $\mathrm{Cmk} 2$ in response to endoplasmic reticulum stresses. Eukaryot. Cell 7, 2037-2051.

Durr, G., Strayle, J., Plemper, R., Elbs, S., Klee, S. K., Catty, P., Wolf, D. H., and Rudolph, H. K. (1998). The medialGolgi ion pump Pmrl supplies the yeast secretory pathway with $\mathrm{Ca}^{2+}$ and $\mathrm{Mn}^{2+}$ required for glycosylation, sorting, and endoplasmic reticulumassociated protein degradation. $\mathrm{Mol}$. Biol. Cell 9, 1149-1162.

Friedman, J. R., and Voeltz, G. K. (2011). The ER in 3D: a multifunctional dynamic membrane network. Trends Cell Biol. 21, 709-717.

Guerin, R., Arseneault, G., Dumont, S. and Rokeach, L. A. (2008). Calnexin is involved in apoptosis induced by endoplasmic reticulum stress in the fission yeast. Mol. Biol. Cell 19, 4404-4420.

Guerin, R., Beauregard, P. B., Leroux, A., and Rokeach, L. A. (2009). Calnexin regulates apoptosis induced by inositol starvation in fission yeast. PLoS ONE 4, e6244. doi: 10.1371/journal. pone.0006244

Han, S., Lone, M. A., Schneiter, R., and Chang, A. (2010). Orm1 and Orm2 are conserved endoplasmic reticulum membrane proteins regulating lipid homeostasis and protein quality control. Proc. Natl. Acad. Sci. U.S.A. 107, 5851-5856.

Harding, H. P., Zhang, Y., and Ron, D. (1999). Protein translation and folding are coupled by an endoplasmicreticulum-resident kinase. Nature 397, 271-274.

Hauptmann, P., and Lehle, L. (2008). Kexl protease is involved in yeast cell death induced by defective $\mathrm{N}$-glycosylation, acetic acid, and chronological aging. J. Biol. Chem. 283, 19151-19163.

Hauptmann, P., Riel, C., KunzSchughart, L. A., Frohlich, K. U. Madeo, F., and Lehle, L. (2006). Defects in $\mathrm{N}$-glycosylation induce apoptosis in yeast. Mol. Microbiol. 59, 765-778.

Henry, S. A., Kohlwein, S. D., and Carman, G. M. (2012). Metabolism and regulation of glycerolipids in the yeast Saccharomyces cerevisiae. Genetics 190, 317-349.

Howarth, D. L., Vacaru, A. M., Tsedensodnom, O., Mormone, E., Nieto, N., Costantini, L. M., Snapp, E. L., and Sadler, K. C. (2012). Alcohol disrupts endoplasmic reticulum function and protein secretion in hepatocytes. Alcohol. Clin. Exp. Res. 36, 14-23.

Hu, J., Prinz, W. A., and Rapoport, T. A. (2011). Weaving the web of ER tubules. Cell 147, 1226-1231.

Hu, J., Shibata, Y., Zhu, P. P., Voss, C., Rismanchi, N., Prinz, W. A. Rapoport, T. A., and Blackstone, C. (2009). A class of dynamin-like GTPases involved in the generation of the tubular ER network. Cell 138 549-561.

Kharroubi, I., Ladriere, L., Cardozo, A. K., Dogusan, Z., Cnop, M. and Eizirik, D. L. (2004). Free fatty acids and cytokines induce pancreatic beta-cell apoptosis by different mechanisms: role of nuclear factorkappaB and endoplasmic reticulum stress. Endocrinology 145 5087-5096.

Kim, H., Kim, A., and Cunningham, K. W. (2012). Vacuolar $\mathrm{H}^{+}$. ATPase (V-ATPase) promotes vacuolar membrane permeabilization and nonapoptotic death in stressed yeast. J. Biol. Chem. 287, 19029-19039.

Kucharz, K., Wieloch, T., and Toresson, H. (2011a). Potassiuminduced structural changes of the endoplasmic reticulum in pyramidal neurons in murine organotypic hippocampal slices. J. Neurosci. Res. 89, 1150-1159.

Kucharz, K., Wieloch, T., and Toresson, H. (2011b). Rapid fragmentation of the endoplasmic reticulum in cortical neurons of the mouse brain in situ following cardiac arrest. J. Cereb. Blood Flow Metab. 31, 1663-1667.

Lesage, G., and Bussey, H. (2006). Cell wall assembly in Saccharomyces cerevisiae. Microbiol. Mol. Biol. Rev. 70, 317-343.

Levin, D. E. (2011). Regulation of cell wall biogenesis in Saccharomyces cerevisiae: the cell wall integrity signaling pathway. Genetics 189, 1145-1175

Lisbona, F., Rojas-Rivera, D., Thielen, P., Zamorano, S., Todd, D., Martinon, F. Glavic, A., Kress, C., Lin, J. H., Walter, P., Reed, J. C., Glimcher, L. H., and Hetz, C. (2009). BAX inhibitor1 is a negative regulator of the ER stress sensor IRE1alpha. Mol. Cell 33, 679-691.

Lyman, S. K., and Schekman, R. (1996). Polypeptide translocation machinery of the yeast endoplasmic reticulum. Experientia 52, 1042-1049.

Madeo, F., Carmona-Gutierrez, D. Ring, J., Buttner, S., Eisenberg, T., and Kroemer, G. (2009). Caspasedependent and caspase-independent cell death pathways in yeast. Biochem. Biophys. Res. Commun. 382, 227-231.

Madeo, F., Herker, E., Maldener, C. Wissing, S., Lachelt, S., Herlan, M. Fehr, M., Lauber, K., Sigrist, S. J., Wesselborg, S., and Frohlich, K. U. (2002). A caspase-related protease regulates apoptosis in yeast. Mol. Cell 9, 911-917.

Oakes, S. A., Opferman, J. T., Pozzan, T., Korsmeyer, S. J., and Scorrano, L. (2003). Regulation of endoplasmic reticulum $\mathrm{Ca}^{2+}$ dynamics by proapoptotic BCL-2 family members. Biochem. Pharmacol. 66, 1335-1340.

Orso, G., Pendin, D., Liu, S., Tosetto, J., Moss, T. J., Faust, J. E., Micaroni, M. Egorova, A., Martinuzzi, A., McNew, J.A., and Daga, A. (2009). Homotypic fusion of ER membranes requires the dynamin-like GTPase atlastin. Nature 460, 978-983.

Parmar, V. M., and Schroder, M (2012). Sensing endoplasmic reticulum stress. Adv. Exp. Med. Biol. 738, 153-168.

Pineau, L., Colas, J., Dupont, S., Beney, L., Fleurat-Lessard, P., Berjeaud, J. M. Berges, T., and Ferreira, T. (2009). Lipid-induced ER stress: synergistic effects of sterols and saturated fatty acids. Traffic 10, 673-690.

Rizzuto, R., Pinton, P., Carrington, W., Fay, F. S., Fogarty, K. E., Lifshitz, L. M., Tuft, R. A., and Pozzan, T. (1998). Close contacts with the endoplasmic reticulum as determinants of mitochondrial $\mathrm{Ca}^{2+}$ responses. Science 280, 1763-1766.

Ron, D., and Walter, P. (2007). Signal integration in the endoplasmic reticulum unfolded protein response. Nat. Rev. Mol. Cell Biol. 8, 519-529.

Sano, R., Hou, Y. C., Hedvat, M., Correa, R. G., Shu, C. W., Krajewska, M., Diaz, P. W., Tamble, C. M., Quarato, G., Gottlieb, R. A., Yamaguchi, M., Nizet, V., Dahl, R., Thomas, D. D. Tait, S. W., Green, D. R., Fisher, P. B., Matsuzawa, S., and Reed, J. C. (2012). Endoplasmic reticulum protein BI-1 regulates $\mathrm{Ca}^{2+}$-mediated bioenergetics to promote autophagy. Genes Dev. 26, 1041-1054.

Schuck, S., Prinz, W. A., Thorn, K. S., Voss, C., and Walter, P. (2009). Membrane expansion alleviates endoplasmic reticulum stress independently of the unfolded protein response. J. Cell Biol. 187, 525-536.

Scorrano, L., Oakes, S. A., Opferman, J. T., Cheng, E. H., Sorcinelli, M. D., Pozzan, T., and Korsmeyer, S. J. (2003). BAX and BAK regulation of endoplasmic reticulum $\mathrm{Ca}^{2+}$ : a control point for apoptosis. Science 300, 135-139.

Shibata, Y., Hu, J., Kozlov, M. M., and Rapoport, T. A. (2009). Mechanisms shaping the membranes of cellular organelles. Annu. Rev. Cell Dev. Biol. 25, 329-354.

Shibata, Y., Shemesh, T., Prinz, W. A., Palazzo, A. F., Kozlov, M. M., and Rapoport, T. A. (2010). Mechanisms determining the morphology of the peripheral ER. Cell 143, 774-788.

Sidrauski, C., and Walter, P. (1997). The transmembrane kinase Irelp is a site-specific endonuclease that initiates mRNA splicing in the unfolded protein response. Cell 90, 1031-1039. Sorin, A., Rosas, G., and Rao, R. (1997). PMR1, a Ca2+-ATPase in yeast Golgi, has properties distinct from sarco/endoplasmic reticulum and plasma membrane calcium pumps. J. Biol. Chem. 272, 98959901.

Strayle, J., Pozzan, T., and Rudolph, H. K. (1999). Steady-state free $\mathrm{Ca}^{2+}$ in the yeast endoplasmic reticulum reaches only 10 microm and is mainly controlled by the secretory pathway pump pmrl. EMBO J. 18, 4733-4743.

Tabas, I., and Ron, D. (2011). Integrating the mechanisms of apoptosis induced by endoplasmic reticulum stress. Nat. Cell Biol. 13, 184-190.

Trusina, A., Papa, F. R., and Tang, C. (2008). Rationalizing translation attenuation in the network architecture of the unfolded protein response. Proc. Natl. Acad. Sci. U.S.A. 105, 20280-20285.

Urano, F., Wang, X., Bertolotti, A., Zhang, Y., Chung, P., Harding, $\mathrm{H}$. P., and Ron, D. (2000). Coupling 
of stress in the ER to activation of JNK protein kinases by transmembrane protein kinase IRE1. Science 287, 664-666.

Vashist, S., Frank, C. G., Jakob, C. A., and Ng, D. T. (2002). Two distinctly localized p-type ATPases collaborate to maintain organelle homeostasis required for glycoprotein processing and quality control. Mol. Biol. Cell 13, 3955-3966.

Voeltz, G. K., Prinz, W. A., Shibata, Y., Rist, J. M., and Rapoport, T. A. (2006). A class of membrane proteins shaping the tubular endoplasmic reticulum. Cell 124, 573-586.

Walter, P., and Ron, D. (2011). The unfolded protein response: from stress pathway to homeostatic regulation. Science 334, 1081-1086.

Wang, X. Z., Harding, H. P., Zhang, Y., Jolicoeur, E. M., Kuroda, M., and Ron, D. (1998). Cloning of mammalian Irel reveals diversity in the
ER stress responses. EMBO J. 17, 5708-5717.

Watanabe, R., and Riezman, H. (2004). Differential ER exit in yeast and mammalian cells. Curr. Opin. Cell Biol. 16, 350-355.

Watson, P., and Stephens, D. J. (2005) ER-to-Golgi transport: form and formation of vesicular and tubular carriers. Biochim. Biophys. Acta 1744 304-315.

West, M., Zurek, N., Hoenger, A., and Voeltz, G. K. (2011). A 3D analysis of yeast ER structure reveals how ER domains are organized by membrane curvature. J. Cell Biol. 193, 333-346.

Wissing, S., Ludovico, P., Herker, E., Buttner, S., Engelhardt, S. M., Decker, T., Link, A., Proksch, A., Rodrigues, F., Corte-Real, M., Frohlich, K. U., Manns, J., Cande, C., Sigrist, S. J., Kroemer, G., and Madeo, F. (2004). An AIF orthologue regulates apoptosis in yeast. J. Cell Biol. 166, 969-974.
Woehlbier, U., and Hetz, C. (2011). Modulating stress responses by the UPRosome: a matter of life and death. Trends Biochem. Sci. 36, 329-337.

Wysocki, R., and Kron, S. J. (2004). Yeast cell death during DNA damage arrest is independent of caspase or reactive oxygen species. J. Cell Biol. 166, 311-316.

Zimmermann, R., Eyrisch, S., Ahmad, M., and Helms, V. (2011). Protein translocation across the ER membrane. Biochim. Biophys. Acta 1808, 912-924.

Zong, W. X., Li, C., Hatzivassiliou, G., Lindsten, T., Yu, Q. C., Yuan, J., and Thompson, C. B. (2003). Bax and Bak can localize to the endoplasmic retic ulum to initiate apoptosis. J. Cell Biol. 162, 59-69.

Conflict of Interest Statement: The author declares that the research was conducted in the absence of any commercial or financial relationships that could be construed as a potential conflict of interest.

Received: 05 May 2012; paper pending published: 31 May 2012; accepted: 17 July 2012; published online: 02 August 2012. Citation: Austriaco N (2012) Endoplasmic reticulum involvement in yeast cell death. Front. Oncol. 2:87. doi: 10.3389/ fonc.2012.00087

This article was submitted to Frontiers in Molecular and Cellular Oncology, a specialty of Frontiers in Oncology.

Copyright (c) 2012 Austriaco. This is an open-access article distributed under the terms of the Creative Commons Attribution License, which permits use, distribution and reproduction in other forums, provided the original authors and source are credited and subject to any copyright notices concerning any thirdparty graphics, etc. 